\title{
Cumplimiento de las Disposiciones del Derecho Canónico
}

Durante siglos en la Iglesia Católica los canonistas han considerado que el centro de la vida eclesiástica era el derecho canónico, y a los sagrados cánones, - o lo que es más grave al aparato de normas y de comentarios que se ha formado alrededor de ellos-, los han elevado a la categoría de leyes intangibles, subordinando todo al "ius canonicum".

Han olvidado ciertamente que "no debe juzgarse según las apariencias, sino según justicia" ( $\mathrm{Jn}$. 7,24) y a semejanza de los rubricistas que confundieron el cumplimiento de las rúbricas con la belleza de la liturgia, muchos seguidores de las normas legales han perdido de vista la finalidad del mensaje evangélico. Algunos han llegado a exclamar que el "Codex iuris canonici" es la Biblia para la vida de la Iglesia y que en él se hallaba solución a todo problema pastoral. De hecho obispos y párrocos, honestamente, han creido cumplir con sus funciones, ciñéndose a las disposiciones canónicas con todo esmero.

De ahí que se haya reducido la misión del obispo a la de un administrador, una especie de gobernador civil que debe vigilar la buena marcha de la administración clerical. En cambio es necesario recuperar la imagen paulina y joánica de la Iglesia que se perdió en la Edad Media; pérdida lamentable pues todavía encuentra esa deformación amplia cabida en el código vigente, dado que el obispado y la parroquia pasaron a ser circunscripciones de gobierno y prebendas más que unidades de acción pastoral y de apostolado. Eran "beneficum" más que "officium".

Evidente que no puede negarse la necesidad de dictar prescripciones para regular la vida de los hombres, y desde los primeros tiempos de la Iglesia, tanto en los Hechos de los Apóstoles como en las Epístolas, se encuentra una multitud de disposiciones que reglamentan la vida de los fieles. No se negará la importancia de la ciencia jurídica para la administración de la Iglesia y la difusión del Evangelio. En las leyes canónicas y en los comentarios jurídicos tenemos un arsenal grandioso, muy útil y necesario para el apostolado moderno, pero no dejemos de preguntarnos chasta que punto debe ser tenida en cuenta la acomodación en la transferencia de las leyes canónićas de un país a otros? ¿Hasta qué punto deberían influir las costumbres populares de aquellos momentos, las exigencias del "hic et nunc"? Evidentemente cabían varias soluciones, de acuerdo con las diversas circunstancias de tiempo. 
Es cierto, dada la penetración del cristianismo en las costumbres populares y patrias del tiempo en que surguieron las leyes canónicas, que la transferencia de esas disposiciones a otros lugares y a otros pueblos tuvo que dar como resultado graves tensiones. Pues no siempre podía crearse una nuva legislación, sino que ésta debía conservarse y mantenerse sustancialmente. Así ella exigía no sólo acomodarse, sino también en cuanto era posible, una recta conservación y una trasmisión fiel. Como la legislación canónica es una expresión formal del mensaje evangélico, y debe evitar los cambios bruscos, debe participar de algún modo de la estabilidad e intangibilidad del anuncio de la Buena nueva y debe comunicar de este modo a los fieles algo de la perennidad de la voluntad Divina.

En este sentido es justificado el anhelo de los canonistas para que las normas de carácter extraordinario concedidas por la Congregación de Propaganda Fide a los misioneros, desaparezcan y se sujeten esos territorios al "ius commune". Pero cpuede afirmarse siempre que las normas comunes son más adecuadas a las necesidades pastorales que las disposiciones contenidas en los índices de facultades otorgadas a los Ordinarios de Misión, a los de América Latina o simplemente en las quinquenales coneedidas a los Obispos de todo el orbe?

El derecho se ha convertido en una serie de normas y prescripciones rígidas, que deben ser observadas estrictamente de acuerdo con las leyes establecidas a las que se procura seguir con santo respeto, pero que finalmente terminan petrificándose. Quizás era necesario este anquilosamiento como protección contra los ataques que la herejía dirigió contra la constitución de la Iglesia, necesario también a fin de conservar la sagrada herencia para los tiempos futuros de la Iglesia, para un tiempo de mayores necesidades y decisiones más importantes, como es el presente tiempo en que vivimos para un tiempo en que los hombres se verán precisados a recibir de la Iglesia aquella orientación de la que participaron los cristianos de los primeros siglos. Así es inadmisible que en el esquema conciliar "de espiscopis" se diga todavía que el obispo debe preocuparse de buscar vocaciones, no solo sacerdotales sino también misioneras y religiosas; debe entenderse que la calificación de "misionero" es inherente al sacerdocio, pues el Maestro nos envió a "predicar a todas las naciones", y por consiguiente debe desapa. recer la figura del sacerdote puramente burócrata o que solo cumple lo mínimo necesario sin tener ningún interés por el apostolado.

Los elementos fundamentales del derecho canónico permanecen siempre los mismos como son idénticos los elementos fundamentales de la pastoral. Pero puede resultar necesario, de tiempo en tiempo, que lo que durante siglos de tranquila inercia se encontraba situado en el fondo como segura posesión, salga a la luz de la conciencia; que de nuevo se vuelva a proclamar la buena nueva de la salvación, que hemos logrado en Cristo, con la fuerza y la claridad originales, en todas las lenguas, en la catequesis y en la predicación, en la estructuración del derecho canónico, en la palabra y en los escritos, para que los hombres vuelvan a reconocer a Aquel que es la luz del mundo.

En la renovada eclesiología conciliar, es notable el redescubrimiento de la noción de la "Iglesia local", la que descubre su plenitud alre- 
dedor de su Bien Común que es la Eucaristía, en la que se incorporan todas las obras de los cristianos, ya sean sagradas o profanas; el Obispo, zunido al centro de la lglesia (el Papa), pero sin ser su delegado, aparece verdaderamente como el sumo sacerdote de su Iglesia diocesana y el jefe de la iniciativa misionera.

El obispo es profeta o doctor de la fe. "Ay de mí si no predicare el Evangelio" repite el obispo con san Pablo (I Cor. 9, 16) pues es su primera misión, porque la fe debe preceder a los sacramentos. Sin embargo prima la costumbre que en las Misas pontificales el obispo celebre y un orador de campanillas pronuncie el panegirico, desvirtuando la primera misión espiscopal.

Como es imposiblé que el obispo pueda enseñar, en persona, debe estar en estrecho contacto y vinculación con sus sacerdotes, religiosos y religiosas, dirigentes seglares para que su enseñanza sea difundida y preparar el personal apto y adecuado para los diferentes ambientes. Su enseñanza la elaborará con la colaboración de las personas informadas, tanto de los expertos en teología y otras ciencias eclesiásticas, como de los laicos comprometidos en el mundo, que son los únicos que pueden proporcionar los datos necesarios sobre la realidad temporal.

Las cartas pastorales deben ser sencillas, sin retórica ni ampulosidad ni términos anticuados que nada expresan a los modernos. Las encíclicas "Mater et magistra" y "Pacem in terris" nos han trazado las huellas a seguir.

El obispo es Pastor de la Iglesia particular. En los últimos tiempos se ha insistido con frecuencia - y era necesario - que la Iglesia local no es una circunscripción administrativa de la Iglesia total. El obispo preside a la Iglesia, siendo al mismo tiempo su primer servidor. Esta concepción transforma muchas maneras de ser. Para actuar en el mundo moderno "socializado" urge volver a las fuentes del Evangelio: en él se encuentra una nítida visión para tratar con el mundo actual, buscando "primero el reino de Dios y su justicia" (Mt. 6, 33).

Los obispos solo pueden predicar a "Cristo y a Este crucificado" (I Cor. 2,2): es la única base sólida para enfrentarse al mundo de hoy. De ahí la urgencia del "aggiornamento" reclamada por Juan XXIIl.

Es indispensable que el obispo tenga presente que él no puede resolver todos los problemas ni asumir todos las mismas actitudes: Pablo VI no es Juan XXIII, ni éste fué Pío XII. Entonces el obispo debe con preferencia atender los aspectos para los que tiene mayor aptitud de acuerdo con su capacidad; y confiar a otros (sacerdotes, religiosos, religiosas y seglares competentes) los asuntos que directamente no puede asumir. Es imposible ser especialista en todo, y al mismo tiempo impartir, orientaciones generales, que por serlo demasiado, son inútiles.

El obispo confiará plenamente en sus colaboradores o subordina. dos, en su competencia y aptitud, sin interferir contínuamente en sus trabajos (aunque a veces no coincidan con sus puntos de vista personales), pues una excesiva intervención en el desenvolvimiento de las labores de los inferiores impiden su eficiente y normal desarrollo. 
Es indudable que toda nuestra acción pastoral ha estado en los últimos tiempos dedicada a conservar un mundo que era cristiano; estabas absorbida por encargos o instituciones que fueron vivas anteriormente, pero que ahora están muriendo. Por cumplir las tradiciones en América Latina, el escaso número de sacerdotes se consagra a ello y está extenuado. por el trabajo, descuidando a los alejados de la Iglesia, que son la gran mayoría. ¿Debe apagarse la chispa? Es cierto que existen feligreses que son fieles, activos, interesados, pero que nos impiden ver a los tibios, a los. indiferentes. En el Perú más del $90 \%$ de los escolares acuden a las escuelas gubernamentales, mientras que menos del $10 \%$ absorben el gran esfuerzo de las instituciones docentes de la lglesia, y es en su gran mayoría la clase rica y poderosa, y el $98 \%$ de la población ha recibido el bautismo dentro de la Iglesia católica. Los fieles, los religiosos, los sacerdotes. todavía no tienen conciencia de la actitud misionera que se requiere hoy para atender el gran número de alejados de la lglesia.

Este cambio de mentalidad exigirá una renovación de las constituciones y formas exteriores de la vida religiosa; por ejemplo santificarse. como los Padres del desierto sin escuchar diariamente la santa Misa, para atender a poblaciones que carecen de sacerdote residente, como ya hacen unas comunidades religiosas en Bolivia y en la diócesis de Natal (Brasil), en la que el obispo ha confiado una parroquia a religiosas con el mandato que preparen el campo para la presencia futura del sacerdote; dichas religiosas hacen todo, con excepción de confesar o celebrar la Misa.

El obispo, desgraciadamente, vive encerrado en un círculo tradicional: curia, sacerdotes, religiosas, personas piadosas, que determinan "lo que su alta investidura no le permite hacer"; y de esa manera le impiden. percibir la realidad actual por carencia de la información necsaria.

Debe romperse esa muralla de "situación constituída" alrededor de la figura del obispo, para que pueda entrar en contacto con la realidad actual de la diócesis. Es imprescindible que el Obispo y sus colaboradores estudien la forma de no vivir en un mundo aparte, a espaldas de la realidad, y menos de recluirse en un "gheto".

El obispo no es administrador de pequeñeces que captan todo su tiempo. Existen en el derecho y en la liturgia multitud de reservaciones episcopales que carecen de objeto, pues siempre tendiá que concederlas o porque no puede conocer todo o porque son mínimas y debe darles. Sin embargo molesta pedirlas y los curiales se sienten muy satisfechos extendiendo documentos o recabando firmas inútiles; por ejemplo bendiciones reservadas de ornamentos, etc., o concesión de licencias ministeriales a religiosos que permanecen en la diócesis 2 ó 3 semanas.

La visita pastoral realizada en la forma tradicional es ineficaz, porque al llegar el obispo la población vive un clima artificial de festejos y recep. ciones; porque la administración de la confirmación emplea la mayor parte del tiempo y con frecuencia se recibe sin adecuada preparación; porque está demasiado dedicada al aspecto material, 'como estado del templo y casa parroquial o burocrático (revisión de cuentas y libros parroquiales). La visita pastoral debe transformarse en un contacto más estrecho y permanente del obispo con sus sacerdotes $y$ dirigentes laicos; vivir en forma 
ordinaria durante una o dos semanas en las parroquias; descubrir la forma de ponerse en contacto con los alumnos de las escuelas (aún religiosas) y con los enfermos de los hospitales sin solemnidad; en una palabra abrir el diálogo.

El cardenal Suenens, hace pocos días, pidió la “internacionalización" de las canoniżaciones pues el actual procedimiento es lento y oneroso, y no permite que se presenten a los cristianos los modelos de santidad que necesitan. Lo mismo debe pedirse para los otros procedimientos canónicos y suprimir tribunales diocesanos que no tienen trabajo o no pueden constituirse por falta de personal competente. El canon 366 párrafo 1 ' prescribe que "siempre que el buen gobierno de la diócesis lo pida se nombrará un Vicario general" . Esta norma debe ser extendida y no querer implantar en todas las diócesis la misma planta de funcionarios, dejando el ministerio pastoral vacante, pues con frecuencia los curiales arman un aparato de formularios, encuestas, circulares, audiencias, etc. que no sirven para nada, olvidando que el derecho y la curia están al servicio de las almas.

Urge la adaptación de la legislación a las peculiares condiciones de cada continente, como señalé en mi artículo "¿es aplicable la legislación canónica en América Latina"; en especial tener en cuenta la diversidad de países y aún de regiones; Así, para la introducción de la lengua vulgar en el Ferú, debe considerarse que no es suficiente la versión al castellano, sino que millones de indígenas solo hablan el quechua o el aimará. Para esto los Concilios provinciales y sínodos diocesanos no deben ser mera repetición del Código, sino adaptar la legislación universal; por ejemplo en las zonas andinas no se conocen las "Juntas de fábrica", pero si el "síndico o fiscal" encargado del cuidado del templo y utensilios sagrados durante la ausencia del párroco, quien solo aparece para las fiestas; sobre este personaje ni los concilios plenario latinoamericano ni limenses, ni el sinodo diocesano dicen nada, en cambio fue establecido por los antiguos misioneros y democráticamente es elegido en asamblea popular y luego confirmado por el párroco o el obispo.

El obispo es Pater et servus, esto es el primer servidor de la diócesis. Esta concepción determina que las diócesis deben ser construídas a medida humana, pues las muy pequeñas solo sirven para satisfacer vanidades pueblerinas o las muy grandes a un ideal de orden externo en demasía y ambas han empobrecido la noción del obispo en cuanto padre de su Iglesia. La extensión superficial y el número de habitantes depende de la comunidad que pueda abarcar una Iglesia local: para que el obispo tengá verdadera responsabilidad personal deberá conocer a sus ovejas y ellas conocerlo a él, en especial sus sacerdotes y seminaristas. Esto será posible si la diócesis tiene una población de 250.000 a medio millón de habitantes; una cantidad superior imposibilita el contacto y el conocimiento del obispo; si la diócesis exige la presencia de un obispo auxiliar por el gran número de fieles, debe ser dividida, porque en esta clase de diócesis entre el obispo y los fieles, y aún entre el obispo y sus sacerdotes, se establece - con frecuencia - un telón de protocolo y burocracia que deforma el sentido de Iglesia local. 
El obispo en su diócesis debe poseer "ipso iure", todas las facultades que exige su oficio de pastor, pontífice y doctor de la fe, salvo la slprema, ordinaria y episcopal potestad del Romano Pontífice sobre la Iglesia universal.

Las grandes ciudades que - en cierto sentido - constituyen una unidad, tedrán necesidad de un obispo - jefe y de varios auxiliares responsables del conocimiento personal de la feligresía en un determinado sector bajo la dirección del primero, centro de la unidad pastoral.

En cambio las diócesis con ménos de 250.000 habitantes reducen al obispo a funciones decorativas o a absorber las tareas de sus subordinados, con el peligro que, al ser trasladado a diócesis más grande, (como se acostumbra en la actual organización eclesiástica), continúe con la miama política de atender pequeñeces sin enfrentarse a los problemas de mayor envergadura y sin precisar una pastoral de amplios horizontes y alcances.

En la actual legislación canónica existe algún vestigio de la Iglesia local, pero que no responde a las exigencias de hoy ni a la mentalidad de los hombres contemporáneos, como el Cabildo Catedral, heredero tal vez del antiguo "presbiyerium", pero ahora inoperante por haberse petrificado. Es indispensable transformarlo en auténtico consejo del obispo, con participación - no en forma vitalicia - de sacerdotes, religiosos de ambos sexos y seglares, para organizar y armonizar la pastoral de conjunto. Así será posible establecer sobre bases sólidas la cooperación de los religiosos con el obispo, pues mantendrán su independencia interna e indispensable para sus propios fines, y se integrarán eficazmente en la pastoral diocesana.

Para alcanzar esta renovación pastoral urge una seria, meditada y profundo revisión de los Seminarios, conservar todo lo bueno que tienen, pero al mismo tiempo aceptar toda las innovaciones que sean necesarias para la formación del sacerdote, el otro Cristo de mañana.

Estas apreciaciones acerca de la renovada visión pastoral de los obispos - basadas en la experiencia de los territorios de América latina deben aplicarse "mutatis mutandis" a los párrocos y otros sacerdotes que ejercen la cura de almas, recordando siempre que el derecho no constituye una norma infalible e inderogable, sino que siempre estará al servicio de la pastoral, esto es facilitar la trasmisión del mensaje evangélico a todas las gentes para que todos los hombres crean "que Jesús es el Mesías, el Hijo de Dios, y para que creyéndole tengan vida en nombr suyo "Jn. 20, 31).

$$
\begin{aligned}
& \text { José Danmert Bellido } \\
& \text { Obispo de Cajamarca. }
\end{aligned}
$$

NOTA.-En el número anterior de Derecho (XXIII) puublicamos otro interesante estudio del Excmo. y Rdmo. Monseñor José Dammert Bellido. Recordamos que el actual obispo de Cajamarca fue Catedrático Titular de Derecho Romano en nuestra Facultad y Catedrático de Derecho Canónico. - Fué Secretario General y Vice-Rector de la Pontificia Universidad Católica. Fué obispo auxiliar de la Arquidiócesis de Lima. 